\title{
Protein expression profiling of nuclear membrane protein reveals potential biomarker of human hepatocellular carcinoma
}

Rizma Khan ${ }^{1}$, Saadia Zahid ${ }^{1}$, Yu-Jui Yvonne Wan², Jameson Forster ${ }^{2}$, A-Bashar Abdul Karim², Atta M Nawabi ${ }^{2}$, Abid Azhar ${ }^{3}$, M Ataur Rahman $^{3}$ and Nikhat Ahmed ${ }^{1 *}$

\begin{abstract}
Background: Complex molecular events lead to development and progression of liver cirrhosis to HCC. Differentially expressed nuclear membrane associated proteins are responsible for the functional and structural alteration during the progression from cirrhosis to carcinoma. Although alterations/ post translational modifications in protein expression have been extensively quantified, complementary analysis of nuclear membrane proteome changes have been limited. Deciphering the molecular mechanism that differentiate between normal and disease state may lead to identification of biomarkers for carcinoma.

Results: Many proteins displayed differential expression when nuclear membrane proteome of hepatocellular carcinoma (HCC), fibrotic liver, and HepG2 cell line were assessed using 2-DE and ESI-Q-TOF MS/MS. From the down regulated set in HCC, we have identified for the first time a $15 \mathrm{KDa}$ cytochrome b5A (CYB5A), ATP synthase subunit delta (ATPD) and Hemoglobin subunit beta (HBB) with 11, 5 and 22 peptide matches respectively. Furthermore, nitrosylation studies with S-nitrosocysteine followed by immunoblotting with anti SNO-cysteine demonstrated a novel and biologically relevant post translational modification of thiols of CYB5A in HCC specimens only. Immunofluorescence images demonstrated increased protein S-nitrosylation signals in the tumor cells and fibrotic region of HCC tissues. The two other nuclear membrane proteins which were only found to be nitrosylated in case of HCC were up regulated ATP synthase subunit beta (ATPB) and down regulated HBB. The decrease in expression of CYB5A in HCC suggests their possible role in disease progression. Further insight of the functional association of the identified proteins was obtained through KEGG/ REACTOME pathway analysis databases. String 8.3 interaction network shows strong interactions with proteins at high confidence score, which is helpful in characterization of functional abnormalities that may be a causative factor of liver pathology.

Conclusion: These findings may have broader implications for understanding the mechanism of development of carcinoma. However, large scale studies will be required for further verification of their critical role in development and progression of HCC.
\end{abstract}

Keywords: Hepatocellular carcinoma, Cytochrome b5A, Two dimensional gel electrophoresis, S-nitrosylation, Proteomics, ESI-Q-TOF MS/MS mass spectrometry

\footnotetext{
* Correspondence: nikhat_ahmed14@yahoo.co.uk

${ }^{1}$ Neurochemistry Research Unit Laboratory, Department of Biochemistry, University of Karachi, Karachi, Pakistan

Full list of author information is available at the end of the article
} 


\section{Introduction}

Hepatocellular carcinoma (HCC) is the third leading cause of cancer related deaths worldwide [1-4], increasing from 1.8 to 2.5 per 100,000 patients. Hepatitis B and $\mathrm{C}$ viral infections are well recognized underlying cause of chronic liver disease leading to HCC whereas dietary exposure to aflatoxin $\mathrm{B} 1$, alcoholic liver dysfunction and autoimmune hepatitis are also renowned risk factors [5-9]. The prognosis of HCC is dismal due to underlying cirrhosis as well as poor tumor response to chemotherapeutic regimens [10-12]. Opportunity for anti-cancer therapy in early stage is overlooked just because of the lack of effective biomarkers $[13,14]$. Complex molecular events lead to development and progression of liver cirrhosis to HCC. Deciphering the molecular mechanism that differentiates between normal and disease state may lead to identification of biomarkers for carcinoma $[15,16]$. Although alterations in protein expression have been extensively quantified during progression from cirrhosis to carcinoma, complementary analysis of nuclear membrane proteome changes has been limited [17].

HCC has been associated with elevated expression of inducible nitric oxide synthase (iNOS), and has been responsible for high-output production of nitric oxide (NO). Innate immune response and inflammation, NO is often highly increased at mRNA and protein levels in patients with chronic HBV and HCV [18-20], hemochromatosis and alcoholic cirrhosis [20] all of which cause predisposition to HCC [21]. Nitrosylation is essential and an important reversible post translational modification (PTM) of proteins [22-24]. It is a potential modulator of cellular processes important for tumorigenesis, apoptotic cell death and inhibition of DNA repair [25-27]. In addition to phosphorylation, DNA repair pathways are regulated at multiple levels by NO key components that depict an important role in pathogenesis of hepatocellular carcinoma [25,28-30].

Here we interrogate the differential proteome profiling in HCC tissues of clinically diagnosed HCC patients, fibrotic liver and HepG2 cell lines as controls. We explored HCC nuclear membrane CYB5A as down regulated and nitrosylated. The altered expression of CYB5A suggests that these proteins may be used as a novel prognostic factor and possibly an attractive target for HCC. CYB5A has been associated with essential cellular processes that include cytochrome P450 mediated metabolism of xenobiotics, drugs [31-34], and homeostasis of cholesterol and steroid hormone [35-37]. Involvement of CYB5A in methemoglobin to hemoglobin reduction in erythrocytes [38], and hydroxylation of $\mathrm{N}$-acetyl-neuraminic acid is also observed [39]. Additionally, naturally existing fusion enzymes include mitochondrial flavocytochrome $b_{2}$ (L-lactate dehydrogenase)
[40], sulfite oxidase [41], the $\Delta^{5}$ and $\Delta^{6}$-fatty acid desatu rases (stearyl-CoA-desaturase) [42] and yeast inosi tolphosphorylceramide oxidase also contains CYB5A as a domain component [43].

\section{Results}

\section{Differential assessment of HCC proteome}

In an effort to profile differentially expressed proteomic alterations in $\mathrm{HCV}$ infected liver during cancer progression, we used 2-DE coupled with ESI-QTOF MS/MS to determine the relative levels of proteins across HCC and fibrotic liver.

Approximately 864 protein spots were detected on 2DE gels, out of which 76 protein spots exhibit differential expression in HCC as compared to fibrotic liver and HepG2 cell line. The quantity of each spot was normalized as a percentage of the total quantity of all gel spots. Differentially expressed proteins were defined as statistically significant on the basis of $>1.5$ fold up and down regulation in HCC patients compared with cell line or more changes in expression intensity $(p<0.05)$. Gel analysis was performed using Progenesis SameSpots v4.5 (Nonlinear Dynamic, UK). Each sample set $(\mathrm{n}=6)$ was analyzed in 5 independent mass spectrometer runs.

The data revealed, for the first time, additional proteins that were dysregulated in HCC compared with fibrotic liver and HepG2 cell line. These include significantly elevated levels of ATPB, fibrinogen beta chain (FIBB), and cytochrome b-c1 complex subunit 1(QCR1). Included among the proteins that were down-regulated and not previously reported were CYB5A, ATPD and HBB well represented in Figure 1A. The protein spots were analyzed by using ESI-QTOF MS/MS. Total of six proteins along with accession no. obtained from SWISS/ Prot and sequence coverage (\%) refers to the percentage of protein sequence coverage, determined by number of matched peptides, and their functions were described in Table 1, Additional file 1. Due to the functional significance of CYB5A, we focused on the decreased expression of CYB5A observed in HCC as compared to fibrotic liver. The protein expression along with MS/MS spectra and matched sequence are shown in Figure 1(B-D). In order to assess the validity of data, we examined the differentially expressed CYB5A protein by western blot. The expression of CYB5A was seen to be relatively down regulated in $\mathrm{HCC}$ as compared to HepG2 cell line and fibrotic liver Figure 2(A-B).

\section{CYB5A is an S-Nitrosylated protein}

CYB5A a key determinant of our study was observed to be differentially S-nitrosylated in HCC, fibrotic liver and even HepG2 cell lines. An increased intensity of Snitrosylation in the fibrotic tissue is revealed by 2-DE-IP and western blot analysis, relatively low intensity in 


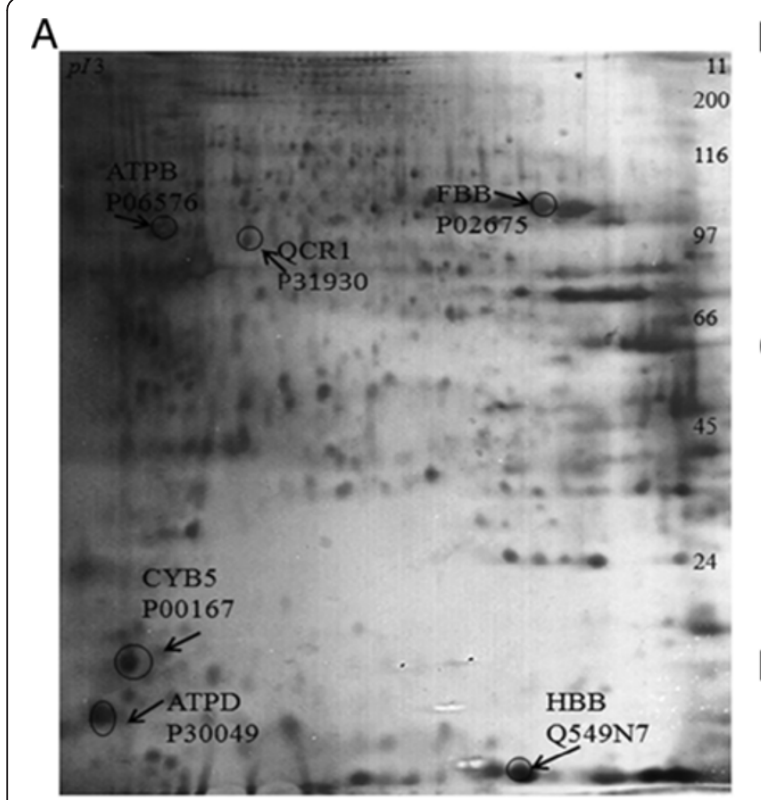

\section{B}
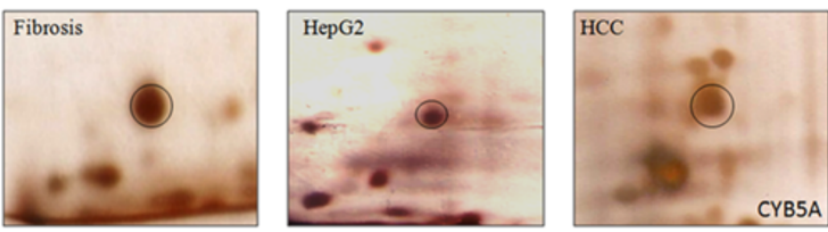

C

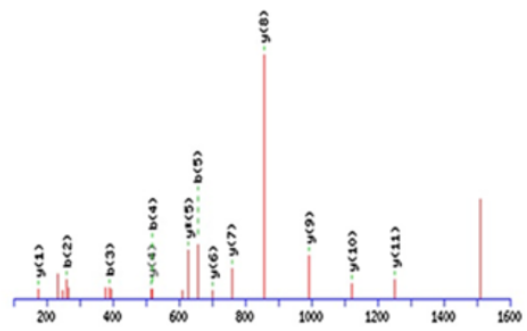

D

1 MAEQSDEAVK YYTLEEIQKHNHSKSTWLILHHKVYDLTKFLEEHPGGEEV 51 LREQAGGDATENFEDVGHSTDAREMSKTFIIGELHPDDRPKLNKPPETLI 101 TTIDSSSSWW TNWVIPAISAVAVALMYRLYMAED

Figure 1 Targeting CYB5A as potential biomarker. (A): in this representative expression profile of significantly up (ATPB, FIBB, and QCR1) and down regulated (CYB5A, ATPD and HBB) proteins in HCC compared with fibrotic liver and HepG2 cell line. Focused on IPG strips pH 3-11 NL (11 $\mathrm{cm}$ ) and separated on $12.5 \%$ gels followed by silver staining. Gel analysis was performed by using Progenesis SameSpots v4.5 (Nonlinear Dynamic, UK). The statistical analysis using Student t-test was performed and on the basis of normalized volumes spots were selected with p-values (< 0.05). (B): Representative protein spot of CYB5A (indicated by circle), showing differential expression between HCC, fibrotic liver and HepG2 cell line. The protein spots were analyzed by using ESI-QTOF MS/MS. (C): Representative MS/MS spectrum and peptide sequence of CYB5A identified by one or more high scoring peptides were considered to be true matches or with extensive homology $(p<0.05)$. b and y represent $b$ ions and $y$ ions respectively, generated during peptide fragmentation in MS/MS. (D): Amino acid sequence of CYB5A, matched peptides were expressed in red type and underline.

HCC and very low in case of cell lines Figure 3(A-B) respectively.

\section{Immunohistolocalization of CYB5A}

IHC analysis of the CYB5A shows significant expression in malignant hepatocytes. However, no expression was observed in portal vein Figure 4(A-B). We also studied disseminated intravascular coagulation (DIC) images, created with Adobe Photoshop CS2 images that exposed the histology and morphology of cells on the same sections. Both immunofluorescence and DIC images were stacked in Figure 4(B). All information related to microscope and camera setting is provided in the supplementary data (Additional file 2).

\section{Immunohistolocalization of S-nitrosylated protein}

Increased S-nitrosylation signal was observed in tumor and fibrous region of HCC tissue as compared to controls Figure 5(A, B \& C). A significant increase in $\mathrm{S}$-nitrosylation intensity of CYB5A is also evident in this regions (Tumor and Fibrosis), revealed by immunofluorescence images Figure 5(C, D \& E). The results presents a massive disruption of lobular manner, portal tract expansion with inflammatory cells in the sinusoids, lymphoid aggregate and hepatocellular apoptosis in the regions with hyper S-nitrosylation signals. The histological and morphological defects were assessed in these regions using Hemotoxylin and Eosin (H\&E) staining prior to the immunoflorescence analysis.

\section{The predicted functional association network of CYB5A}

The functional association network of the identified proteins was generated through protein interaction network STRING 8.3. The interaction patterns will be helpful to have a better understanding of the protein functional activities. As the identified proteins are involved in various cellular/metabolic pathways the close interaction pattern, evident with the high confidence score $>0.7$ are helpful to explicate disease related consequences due to structural and functional perturbations of the expressed protein Figure 6. CYB5A is a membrane bound hemoprotein strongly interacting with its class member CYB4R3 (cytochrome b5 reductase 3), CYP17A1 (Cytochrome P450 family 17, subfamily A, polypeptide 1), CYP3A5 (Cytochrome P450 family 3, subfamily A, polypeptide 5). Possible strong interaction with FADS2 (fatty acid desaturase 2), SCD (stearoyl-CoA desaturase), ACSL1, L2, L3 and L4 (acyl-CoA synthetase, long chain family member 1, 2, 3and 4 respectively) are also observed Figure 6. 
Table 1 Differentially expressed HCC, fibrotic liver nuclear membrane proteins and HepG2 cell line

\begin{tabular}{|c|c|c|c|c|c|c|c|c|c|c|c|c|c|}
\hline \multirow[t]{2}{*}{ Acc } & \multirow[t]{2}{*}{ Name } & \multirow[t]{2}{*}{ Abb } & \multirow[t]{2}{*}{$\begin{array}{l}\text { Thr. } \\
\text { pl; } \\
\text { mass }\end{array}$} & \multirow[t]{2}{*}{ Score } & \multirow[t]{2}{*}{$\begin{array}{l}\text { Peptide } \\
\text { matched }\end{array}$} & \multirow[t]{2}{*}{$\begin{array}{l}\text { Cellular } \\
\text { compartment }\end{array}$} & \multirow[t]{2}{*}{ PTM } & \multirow[t]{2}{*}{$\begin{array}{l}\% \\
\text { age } \\
\text { cov }\end{array}$} & \multicolumn{2}{|c|}{$\begin{array}{l}\text { Mean } \\
\text { normalized } \\
\text { volume fibrosis } \\
\text { HCC /HepG2 }\end{array}$} & \multirow[t]{2}{*}{ Ratio } & \multirow[t]{2}{*}{$\begin{array}{l}\text { Anova } \\
\text { (P) }\end{array}$} & \multirow[t]{2}{*}{$\begin{array}{l}\text { Fold } \\
\text { change }\end{array}$} \\
\hline & & & & & & & & & & & & & \\
\hline \multirow[t]{3}{*}{ P30049 } & \multirow[t]{3}{*}{$\begin{array}{l}\text { ATP synthase } \\
\text { subunit delta }\end{array}$} & \multirow[t]{3}{*}{ ATPD } & \multirow[t]{3}{*}{$\begin{array}{l}5.38 \\
17\end{array}$} & \multirow[t]{3}{*}{58} & \multirow[t]{3}{*}{5} & mitochondrion & $\begin{array}{l}\text { Isopeptide } \\
\text { bond }\end{array}$ & \multirow[t]{3}{*}{$17 \%$} & \multirow[t]{3}{*}{0.02536} & \multirow[t]{3}{*}{0.00704} & \multirow[t]{3}{*}{0.277} & \multirow[t]{3}{*}{0.02} & \multirow[t]{3}{*}{3.6} \\
\hline & & & & & & Mitochondrion & $\begin{array}{l}\text { Ubl } \\
\text { conjugation }\end{array}$ & & & & & & \\
\hline & & & & & & $\begin{array}{l}\text { inner } \\
\text { membrane }\end{array}$ & & & & & & & \\
\hline \multirow[t]{4}{*}{ P02675 } & \multirow{4}{*}{$\begin{array}{l}\text { Fibrinogen beta } \\
\text { chain }\end{array}$} & \multirow[t]{4}{*}{ FIBB } & \multirow{4}{*}{$\begin{array}{l}8.54 \\
55\end{array}$} & \multirow[t]{4}{*}{1009} & 27 & Secreted & Disulfide bond & $41 \%$ & 0.03364 & 0.01628 & 0.483 & 0.05 & 2.1 \\
\hline & & & & & & & Glycoprotein & & & & & & \\
\hline & & & & & & & Pyrrolidone & & & & & & \\
\hline & & & & & & & carboxylic acid & & & & & & \\
\hline P06576 & $\begin{array}{l}\text { ATP synthase } \\
\text { subunit beta }\end{array}$ & ATPB & $\begin{array}{l}5.26 \\
56\end{array}$ & 670 & 18 & $\begin{array}{l}\text { CF(1), } \\
\text { Membrane }\end{array}$ & Acetylation & $29 \%$ & 0.03448 & 0.00913 & 0.264 & 0.04 & 3.7 \\
\hline & & & & & & mitochondrion & Phosphoprotein & & & & & & \\
\hline & & & & & & $\begin{array}{l}\text { Mitochondrion } \\
\text { inner } \\
\text { membrane }\end{array}$ & & & & & & & \\
\hline Q549N7 & Hemoglobin & $\mathrm{HBB}$ & $6.75 ; 15$ & 484 & 22 & Heptoglobin- & Acetylation & $61 \%$ & 0.22697 & 0.11803 & 0.520 & 0.01 & 1.9 \\
\hline & & & & & & hemoglobin & Glycation & & & & & & \\
\hline & & & & & & complex & Glycoprotein & & & & & & \\
\hline & & & & & & & Phosphoprotein & & & & & & \\
\hline & & & & & & & S-nitrosylation & & & & & & \\
\hline P00167 & Cytochrome b5 & CYB5A & 4.88; & 176 & 11 & Cytoplasmic & Acetylation & $42 \%$ & 0.01948 & 0.05883 & 3.020 & 0.04 & 3.0 \\
\hline & & & 15 & & & Endoplasmic & & & & & & & \\
\hline & & & & & & reticulum & & & & & & & \\
\hline & & & & & & Membrane & & & & & & & \\
\hline & & & & & & Microsome & & & & & & & \\
\hline P31930 & Cytochrome b- & QCR1 & 5.94 & 149 & 10 & Mitochondrion & Acetylation & $15 \%$ & 0.01607 & 0.00505 & 0.314 & 0.05 & 3.1 \\
\hline & subunit 1 & & $\mathrm{~s}$ & & & $\begin{array}{l}\text { inner } \\
\text { membrane }\end{array}$ & Phosphoprotein & & & & & & \\
\hline
\end{tabular}

Accession no. is obtained from SWISS/Prot and percent coverage refers to the percentage of protein sequence coverage, determined by number of matched peptides. Significance was calculated from the Progenesis SameSpots v4.5 (Nonlinear Dynamic, UK), generated statistical analysis. A value of $p<0.05$ was considered statistically significant. Functional classes were determined by searching the UniProt database (www.uniprot.org).

The proteins were separated on 2DE gels and identified by ESI-QTOF MS/MS.

\section{Pathway enrichment analysis related to HCC pathology}

Having validated our Mass spectrometry result of CYB5A, we delineated the biological function associa ted with this elevated protein alterations based on the known protein functions according to SWISS-PROT (http://www.expasy.org), classifications provided in the KEGG database (http://www.genome.jp/kegg), GO annotation (http://www.geneontology.org), Reactome, Uniprot, ENSEMBL, PINC analysis pathway and Panther classification system. This process allowed us to identify pathways that are deregulated during HCC development and progression. This exercise revealed the involvment of CYB5A in vitamin $\mathrm{C}$ (ascorbate) metabolism, metabolism of water-soluble vitamins and cofactors, metabolism of vitamins and cofactors, transport, L-ascorbic acid metabolic process, electron transport chain, small mole cule metabolic process, aldo-keto reductase (NADP) activity, amino sugar and nucleotide sugar metabolism http://www.reactome.org.

\section{Discussion}

The current study identifies novel nuclear membrane biomarkers for HCC. Out of 76 differentially expressed proteins, six proteins ATPD, FIBB, ATPB, HBB, CYB5A, 


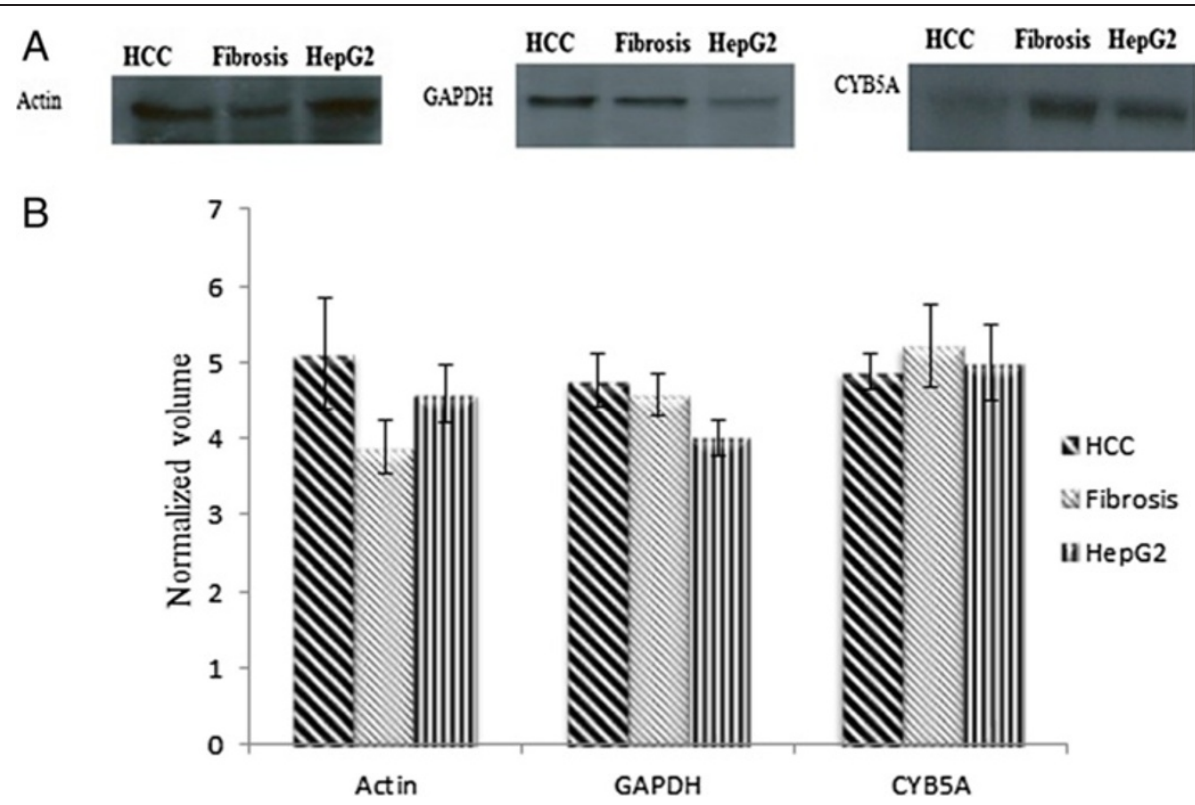

Figure 2 Immunoblot analysis confirms changes in protein expression of CYB5A. (A): representative western blot analysis of CYB5A in HCC,

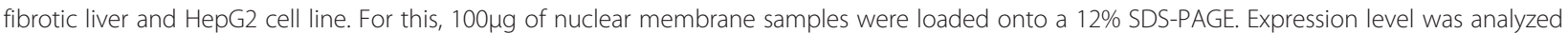
using the primary antibody CYB5A (1:1000 dilution) and horse raddish peroxidase (HRP) - conjugated secondary antibody (1: 5000 dilution). B-actin and GAPDH were used as a loading control. (B): representative graphical expression of validated proteins by western blotting. Digital images were taken by gel documentation system (Bio-Rad). Quantification and intensity measurement of protein bands were analyzed by Quantity One gel analysis software (Bio-Rad). Statistical significance ( $p$ - value > 0.05) was calculated using SPSS statistics version 17.

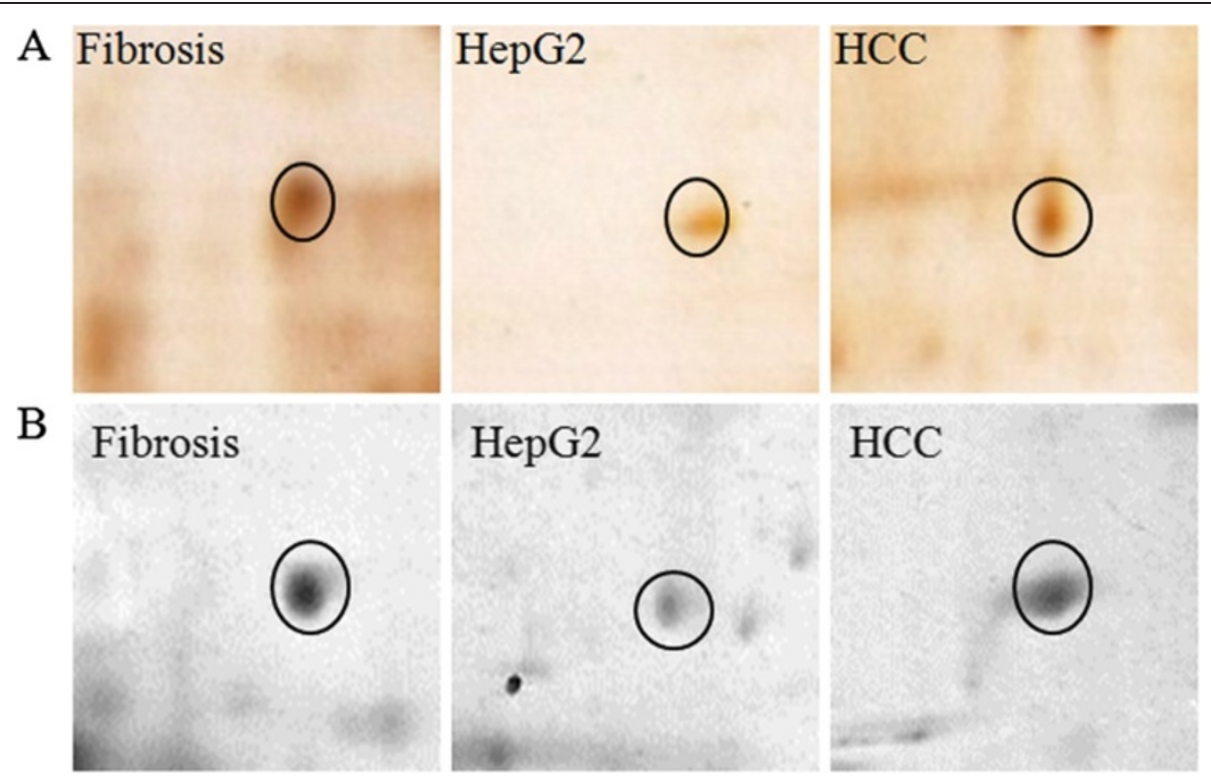

Figure 3 Antibody based identification of CYB5A as S-nitrosylated protein. (A): 2DE Spot representative differential expression level of CYB5A as S-nitrosylated protein in HCC compared with respective fibrotic liver and HepG2 cell line. The proteins were immuno-precipitated with anti SNO-Cys antibody, focused on IPG strips (pl 3-11NL; $7 \mathrm{~cm}$ ) and separated on 12.5\% gel followed by silver staining. (B): Representative spots of CYB5A immuno-precipitated with anti SNO-Cys antibody. $100 \mu \mathrm{g}$ proteins were focused using pl 3-11NL (7 cm) IPG strips and separated on $12.5 \%$ gel followed by western blotting described in material and methods. Densitrometric analysis was performed using Progenesis SameSpots v4.5 (Nonlinear Dynamic, UK). 

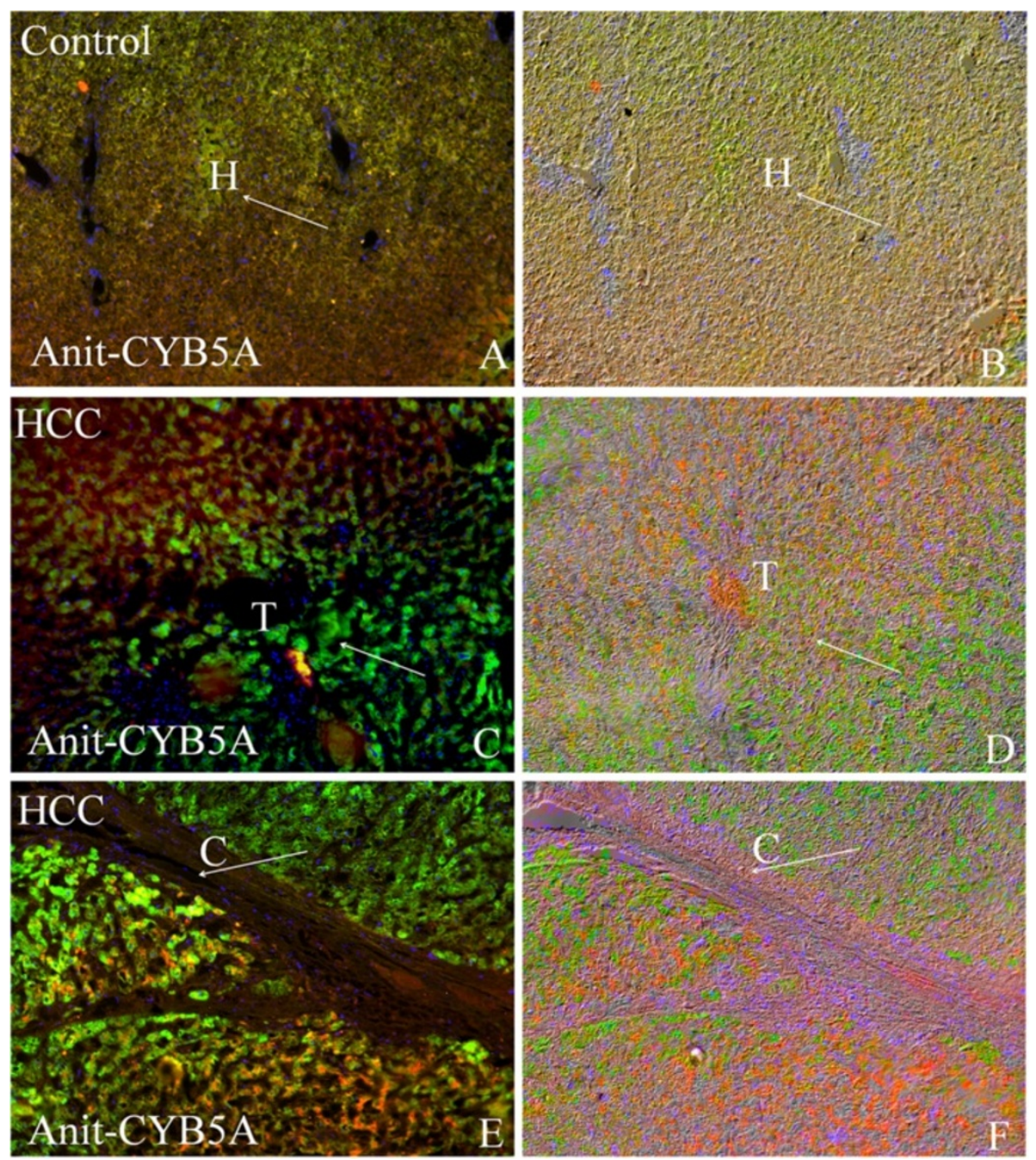

Figure 4 Immunofluorescence analysis of CYB5A in HCC. The IHC image of CYB5A staining in control (A) and hepatocellular carcinoma (C \& E) formalin fixed paraffin embedded (FFPE) section. The section was pre-treated using heat mediated antigen retrieval with sodium citrate buffer for $30 \mathrm{~min}$. The section was then incubated with CYB5A, $5 \mu \mathrm{g} / \mathrm{ml}$, for $1 \mathrm{hr}$ at $40^{\circ} \mathrm{C}$. The secondary antibody (green) was Alexa Fluor $488 \mathrm{goat}$ anti-mouse $\operatorname{lgG}(\mathrm{H}+\mathrm{L})$ used at a $1 / 1000$ dilution for $30 \mathrm{~min}$ at $40^{\circ} \mathrm{C}$. DAPI was used to stain the cell nuclei (blue) at a concentration of $1.43 \mu \mathrm{M}$. (B, D \& F): combination of DIC images and IHC of control and HCC respectively, work done by Adobe Photoshop CS2. (C=Portal tract; H=Normal hepatocytes; T=Malignant hepatocytes; Original magnification= 20X). IHC: Immunohistolocalization.

and QCR1 were quantified across the specimens and delineated into liver fibrosis and carcinoma specific proteins. CYB5A trapped our main focused not only because of lack of information regarding its sub cellular location and down regulation in nuclear membrane of HCC compared to fibrotic liver and HepG2 cell lines, but also because of S-nitrosylation of this protein. Interestingly, CYB5A is characterized by the presence of 3 welldefined phosphorylation sites as demonstrated by the insilico analysis (NetPhosK 1.0). It is likely that incomplete phosphorylation, (may be due to nitrosylation) i.e. not all monomers are phosphorylated, may interfere with protein function. Emerging data suggests that CYB5A and other nuclear proteins are involved in HCC progression [44-46]. Further study will be required to clarify how phosphorylation and nitrosylation influence HCC and the consequent expression of proteins.

Validation by western blotting, immunoprecipitation and immunohistochemical studies revealed the characterized pattern in malignant cells and nuclei but was absent in portal tract. These results allow us to propose sub cellular localization of CYB5A as down regulated nuclear membrane protein with a mechanism proposed in various pathophysiological conditions as aberrant $S$ nitrosylation, caused by altered NO production. So we can say that, decreased expression could leave the liver 

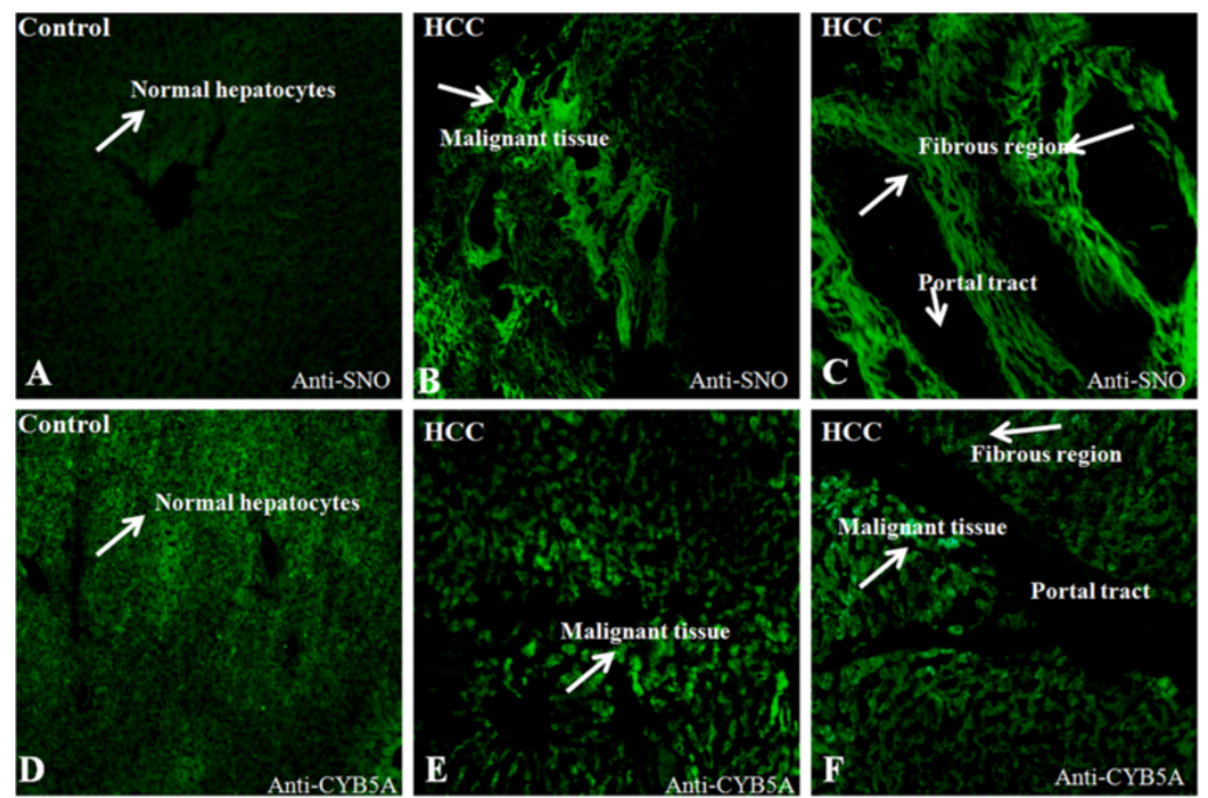

Figure 5 Evidence of S-nitrosylation in HCC: Increased S-nitrosylation is evident in the fibrous portion and tumor cells in HCC. Anti SNO-Cys antibody was used to reveal the distribution of S-nitrosylation signals in the HCC and controls. Significant increase CYB5A is also evident in both fibrous and tumor cells similar to S-nitrosylation. Figure $\mathbf{A} \& \mathbf{D}$ represents control liver on the other side $\mathbf{B}, \mathbf{C}, \mathbf{E}, \mathbf{F}$ explained strong S- nitrosylation signals in HCC.

predisposed to the oncogenic effects of nitrosative stress. Additional study is needed to determine whether NO production induces post-translational modifications of protein and modulates protein function in HCC cell. However, due to the absence of cysteine residue in the CYB5A protein sequence, we propose that the other thiol groups are nitrosylated in the studied HCC specimens.
Understanding towards the disease progression requires complete knowledge interrelated to different pathways and their involvement with the altered proteins.

We conducted STRING 8.3 generated patterns which demonstrated direct interaction of these metabolic proteins with other associated proteins, CYB4R3, CYP17A1, CYP3A5 FADS2 SCD and ACSL1, has an essential role

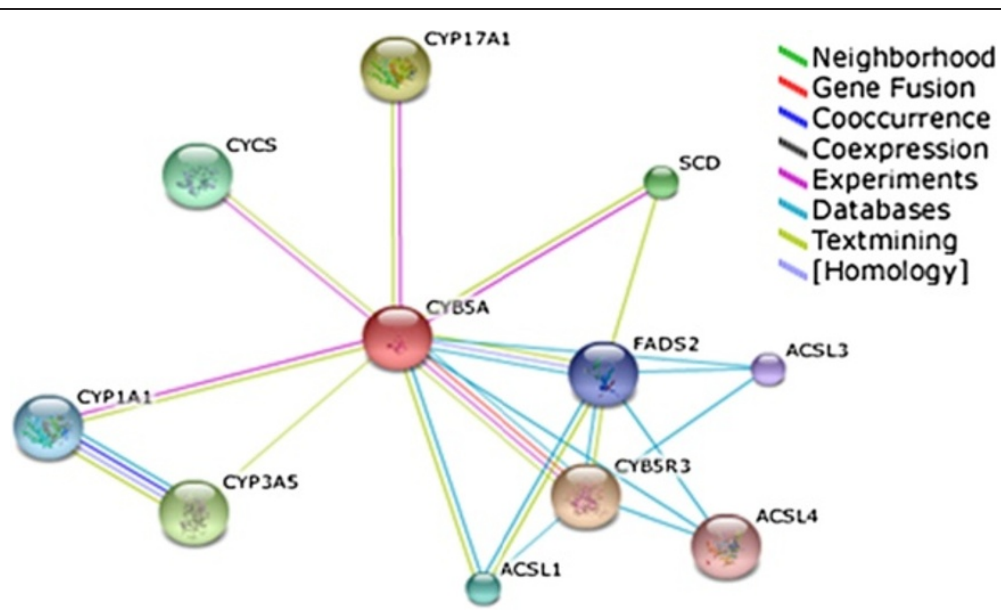

Figure 6 Functional association network of CYB5A. High-confidence protein-protein interaction network of identified nuclear membrane proteins derived from the STRING database (http://string-db.org/). Each protein is represented as a node with edged interactions. (CYB4R3: cytochrome b5 reductase 3; CYP17A1: Cytochrome P450 family 17 subfamily A polypeptide 1; CYP3A5: cytochrome P450 family 3, subfamily A, polypeptide 5; FADS2: fatty acid desaturase 2; SCD: stearoyl-COA desaturase; ACSL1, L2, L3 and L4: acyl-CoA synthetase, long chain family member $1,2,3$ and 4 respectively). 
in the oxidative reaction, anabolic metabolism of fat and steroids, catabolism of xenobiotics and endogenous metabolism [47]. It also has a rather complex interaction with Cytochrome P450 and stimulates its related metabolism $[33,48,49]$.

Insilico studies revealed the role of CYB5A in aldoketo reductase (NADP) activity, cytochrome-c oxidase activity, enzyme binding, heme binding as reflected by the KEGG/REACTOME pathway analysis. Its involvement in respiratory electron transport chain, lipid metabolic pathway was further elaborated by Panther classification (www.panther.com). Several lines of evidence provide insight into potential mechanism by which CYB5A may affect HCC progression and associated pathological condition $[25,27]$. In our case, the presence of 15 -KDa CYB5A fragment in the HCC specimens compared to fibrotic liver and HepG2 cell lines clearly indicates the possible role of this protein in cancer progression. The novel discovery of a membrane protein CYB5A down regulation and its localization coupled with the observation of intense nitrosylation signals in the regional architecture of cirrhotic tissue strongly suggests a major role of CYB5A in the physiology and pathophysiology of HCC.

\section{Conclusion}

Our study suggests that nuclear membrane proteins may have a role in progression from fibrosis to liver carcinogenesis. The molecular mechanisms controlling CYB5A expression and function are of paramount importance. Moreover, target protein activation may be influenced by nitrosylation, might represent a mechanism insuring that a cirrhotic tissue development process was underway where CYB5A and other different proteins can be applied to post translation regulation. In this regard recent studies are beginning to establish biochemical connections between different proteins and cell signaling molecules. Further work must be performed to determine whether these changes are essential and appropriate for $\mathrm{HCC}$ diagnosis and prognosis.

\section{Material and methods}

\section{Tissue procurement}

The Institutional Review Board of University of Kansas Medical Center (USA) and University of Karachi, Pakistan approved this study on discovery of nuclear membrane proteome of liver cancer. Well characterized HCV-associated HCC liver tissues $(n=50)$ were by Kansas Medical Center (KUMC) Liver Bank, USA and Karachi hospitals [male 25 age in mean + SD $53 \pm 7.06$ ); female $=25(51.1 \pm 3.35)]$ while the fibrotic liver tissue $[n=65 ;$ male $=45(49.4 \pm 5.8) \&$ female $=20(47.4 \pm 5.4)]$ were collected only from Karachi, Pakistan with confirmed clinical and genotype report. Tissues were snapfrozen in dry ice and stored at $-80^{\circ} \mathrm{C}$.

\section{Extraction of protein from HCV infected liver}

For protein extraction, samples [HCC $(n=50)$ fibrotic liver $(n=65)$ ] were immersed into PBS (phosphate buffer saline) buffer and washed. Homogenized in adequate volume of homogenization medium (0.25 $\mathrm{M}$ sucrose and $10 \mathrm{mM}$ HEPES, $\mathrm{pH} 7.5$ ), and centrifuged at 1000xg for $10 \mathrm{~min}$. The pellet and supernatant were collected and the supernatant resuspended with buffer A (0.3 M sucrose, $50 \mathrm{mM}$ tris, and $3 \mathrm{mM} \mathrm{MgCl}_{2}, \mathrm{pH} 7.5$ ) and buffer B (1.98 M sucrose, $50 \mathrm{mM}$ tris, $1 \mathrm{mM} \mathrm{MgCl} 2$, $\mathrm{pH}$ 7.5), centrifuged at 70,000xg for 90 min (Optima L100 XP, Beckman Coulter, USA).Protease (Cocktail tablet, Roche, Germany) and phosphatase inhibitors (0.2 mM sodium orthovanidate $\mathrm{Na}_{3} \mathrm{Vo}_{4}$ and $1 \mathrm{mM}$ sodium fluoride $\mathrm{NaF}$ ) were added at every step [17]. The pellet containing nuclei fraction was collected and resuspended in lysis buffer (7 M urea, $2 \mathrm{M}$ thiourea, 4\% CHAPS, $30 \mathrm{mM}$ tris- $\mathrm{Cl}, \mathrm{pH}$ 8.5, protease inhibitor mixture), stored at $-80^{\circ} \mathrm{C}$. Total protein content was measured using the Bradford protein assay.

\section{Cell culture and cell lysis}

HepG2 cell line grown in Dulbecco's modified Eagle medium (DMEM) containing 10\% fetal calf serum (FCS) was used. Briefly, cells were rinsed with DMEM and removed from the flask by incubating with a solution containing trypsin $(0.5 \mathrm{~g} / \mathrm{l})$ and EDTA $(0.2 \mathrm{~g} / \mathrm{l})$. The cells were detached from the surface of the flask by squirting the solution onto the cells. The suspension was centrifuged at 1000xg for $5 \mathrm{~min}$ and the cells washed with DMEM without FCS. After centrifugation and removal of DMEM, cells were mixed and solubilized. The cells were washed twice by centrifugation in PBS and transferred to sterile tubes for storage at $-80^{\circ} \mathrm{C}$ until further analysis.

\section{Two dimensional gel electrophoresis (2DE)}

Isoelectric focusing was performed on Multiphor II system (Amersham GE-Health, Sweden). Briefly, $300 \mu \mathrm{g}$ nuclear membrane protein of HCC, fibrotic liver and HepG2 cell line were dissolved in rehydration buffer (7 M urea, 2 M Thiourea, 4\% CHAPS (3-[(3-cholamidopropyl) dimethylammonio]-1-propanesulfonate), 0.2\% Ampholyte, $15 \mathrm{mM}$ DTT (Dithiothreitol) and trace amount of bromophenol blue) and applied to IPG strips $(11 \mathrm{~cm}$, $\mathrm{pH} 3-10, \mathrm{NL}$ ) allowing to rehydrate overnight. The focusing was carried out at $20^{\circ} \mathrm{C}$, following gradient change in voltage: $500 \mathrm{~V}$ for $1 \mathrm{~h}$, gradient up to $1000 \mathrm{~V}$ over $1 \mathrm{~h}$, gradient to $5000 \mathrm{~V}$ over $1 \mathrm{~h}$, and focusing was continued at $5000 \mathrm{~V}$ for $8.5 \mathrm{~h}$ to give a total of $64 \mathrm{kVh}$. Later the IPG strips were subjected to a two step reduction and alkylation by equilibrating the strips for $20 \mathrm{~min}$ in $50 \mathrm{mM}$ Tris-HCl, $\mathrm{pH}$ 8.8, $6 \mathrm{M}$ urea, 30\% glycerol, 2\% SDS, bromophenol blue, and $0.5 \%$ DTT, followed by another 
20 min in 50 mM Tris-HCl, pH 8.8, 6 M urea, 30\% glycerol, 2\% SDS (sodium dodecyl sulphate), bromophenol blue and $4.5 \%$ iodoacetamide (IAA) at room temperature. Second dimension was conducted in $1 \mathrm{~mm}$ thick $12.5 \%$ polyacrylamide gels at $100 \mathrm{~V}$ for $6 \mathrm{~h}$. The gels were visualized by silver staining [50], each sample were performed in triplicate. Digital images of the gels were taken by gel documentation system (BioRad, USA).

\section{Western blotting}

Nuclear fractionated proteins $(100 \mu \mathrm{g})$ were transferred electrophoretically (100 V for $4 \mathrm{hr}$ ) onto PVDF (Polyvinylidene fluoride) membrane (Amersham, GE Health, Sweden). The membranes were blocked with $5 \%$ BSA (bovine serum albumin) for $1 \mathrm{~h}$ at $4^{\circ} \mathrm{C}$ and incubated overnight with primary antibody anti- cytochrome b5A (ABCAM-UK) (1:1000 dilutions). The blots were washed three times with TBST (Tris-buffered saline with Tween) buffer and incubated for $1 \mathrm{hr}$ at $4^{\circ} \mathrm{C}$ with goat polyclonal rabbit IgG (ABCAM-UK) (1: 5000 dilutions). Immunoblots signals were developed by chromomeric substrate-3, 3'-diaminobenzidine (DAB, Sigma-UK).

\section{Immunoprecipitation and 2DE (IP-2DE)}

Tissue homogenates were prepared with hand homogenizer (Pyrex, Japan) by suspending the tissues in lysis buffer (7 M urea, $2 \mathrm{M}$ thiourea, $0.4 \%$ CHAPS) 'containing protease and phosphatase inhibitors (Roche, Germany). Sepharose $\mathrm{G}$ beads suspension $(50 \mu \mathrm{l})$ (Protein-G sepharose 4 fast Flow, GE Healthcare, Life Sciences, Sweden), was centrifuged at 2000-3000 rpm for $2 \mathrm{~min}$. The pellet was mixed with $450 \mu \mathrm{l}$ HEPES (4-(2-hydroxyethyl)-1piperazineethanesulfonic acid) buffer (50 mM HEPES $\mathrm{pH}$ 7.6, $200 \mathrm{mM} \mathrm{NaCl}, 0.4 \%$ CHAPS) and centrifuged again. The washing steps were repeated four times and HEPES buffer $(450 \mu \mathrm{l})$ was added to the pellet and vortex again. Protein extract $(0.4 \mathrm{mg} / \mathrm{ml})$ was diluted with HEPES buffer to a final volume of $300 \mu \mathrm{l}$ and washed protein $\mathrm{G}$ sepharose $(200 \mu \mathrm{l})$ was added and incubated for $30 \mathrm{~min}$ at $4^{\circ} \mathrm{C}$ with continuous shaking. The sample was then centrifuged at $13000 \mathrm{rpm}$ at $4^{\circ} \mathrm{C}$ for $5 \mathrm{~min}$. The supernatant was incubated overnight with $5 \mu \mathrm{l}$ of anti-S-nitroso-cysteine (SNO-Cys) antibody (ABCAM, UK) at $4^{\circ} \mathrm{C}$. Activated protein $\mathrm{G}$ sepharose beads $(140 \mu \mathrm{l})$ was added and mixed for $4 \mathrm{~h}$ at $4^{\circ} \mathrm{C}$ with continuous shaking and centrifuged for 2-3 $\mathrm{min}$ at $15000 \mathrm{rpm}\left(4^{\circ} \mathrm{C}\right)$. The pellet was washed with HEPES buffer, four times and mixed with $140 \mu \mathrm{l}$ lysis buffer (7 M urea, $2 \mathrm{M}$ thiourea, $0.4 \%$ CHAPS, 1\%Ampholyte) for $1 \mathrm{~h}$ with continuous shaking at room temperature. The sample was centrifuged at $13000 \mathrm{rpm}$ at $4^{\circ} \mathrm{C}$ for $5 \mathrm{~min}$ and the pull-down was solubilized in rehydration buffer and separated by $2 \mathrm{DE}$ on $7 \mathrm{~cm} \mathrm{pH} \mathrm{3-10} \mathrm{NL}$ immobilized $\mathrm{pH}$ gradients (IPG) strips. The strips were rehydrated overnight at room temperature. Isoelectric focusing was started at $500 \mathrm{~V}$ for $1 \mathrm{~h}, 1000 \mathrm{~V}$ for $1 \mathrm{~h}$ with gradual increase to $5000 \mathrm{~V}$ and kept constant for a total of $12000 \mathrm{Vh}$. The gel strips equilibration and second dimension was performed as mentioned above.

\section{Immunoblotting using S-nitrosothiol specific antibody}

Total protein extracts were also used for immunoblotting using SNO-Cys antibody. $100 \mu$ g protein was dissolved in rehydration buffer and IPG strips (7 cm, 3-10 NL) were rehydrated overnight. 2-DE was performed according to the same procedure as in section of Immuno-precipitation (IP-2D). The separated proteins were electrotransferred to PVDF membranes at $30 \mathrm{~mA}$ for $2 \mathrm{~h}$ on Wet Blot (Bio-Rad, USA) that later blocked with $5 \%$ TBST/milk for $1 \mathrm{~h}$ at room temperature. After blocking reaction, the blot was incubated in anti SNO-Cys antibody (1:2000) overnight at $4^{\circ} \mathrm{C}$. Secondary antibody goat anti rabbit IgG HRP was applied (1:1000) for $1 \mathrm{~h}$. The blots were thoroughly washed and developed with ECL (Amersham GE), detected on exposure film (Amersham GE, Sweden) and scanned with Canon flatbed scanner (Canon, UK).

\section{Imaging and statistical analysis}

Gels were analyzed by Progenesis SameSpots v4.5 (Nonlinear Dynamic, UK) according to manufacture recommendation. Protein spots that were differentially expressed in tissue specimen and cell line were marked. Only spots altered consistently were selected for identification. Statistical analysis was performed using the SPSS statistics version 17.

\section{Immunofluorescence Staining}

After de-paraffinization and rehydration by xylol different percentage of isopropanol, heat induced antigen retrieval was performed by immersing HCC liver section slides in a pre-heated steamer containing citrate buffer $\left(95-100^{\circ} \mathrm{C}\right)$ for $30 \mathrm{~min}$. Sections were blocked with Roti block (Roth, Karlsruhe, Germany) with 1:10 dilution, later washed with PBS (Phosphate buffer saline) and incubated with anti CYB5A antibody (ABCAM, UK) for $1 \mathrm{~h}$ at $40^{\circ} \mathrm{C}$. After several steps washing membrane was incubated with secondary antibody, Alexa 488 anti-rabbit (ScantaCruze, California) for $30 \mathrm{~min}$. Another slide of same samples were incubated with anti SNO-Cys antibody for $1 \mathrm{hr}$ at $40^{\circ} \mathrm{C}$ followed by incubation with secondary antibody, Alexa 488 anti-rabbit for $1 \mathrm{~h}$ while nuclei were stained with DAPI for $2 \mathrm{~min}$. Microscopic examination was performed on Eclipse TE2000E epi-flourescence microscope (Nikon, Japan). Images were acquired by DS-Qi1 processed using NIS-Elements software (Nikon Japan). 


\section{Protein identification by electrospray ionization quadrupole time of flight tandem mass spectrometry (ESI-QTOF MS/MS)}

Peptide analyses were carried out on an ESI-QTOFtandem MS system (Waters) and in-gel digestion was performed as described [51] with slight modification. Briefly, gel slices were destained with the mixture of $15 \mathrm{mM} \mathrm{K}_{3} \mathrm{Fe}(\mathrm{CN})_{6}$ and $50 \mathrm{mM} \mathrm{Na} \mathrm{S}_{2} \mathrm{O}_{3}$, washed with deionized water and dehydrated with $\mathrm{ACN}$. The spots were incubated with $100 \mathrm{mM}$ ammonium bicarbonate, washed again and vacuum dried. Proteins were in-gel digested with sequencing grade modified trypsin (The slices were rehydrated for digestion with $40 \mu$ l trypsin (10 ng/ $\mu \mathrm{l}$ in $100 \mathrm{mM}$ ammonium bicarbonate, $\mathrm{pH} 7.4$; Promega, Mannhein, Germany) for $45 \mathrm{~min}$. Excess trypsin solution was removed and the volume replaced with $100 \mathrm{mM}$ ammonium bicarbonate without trypsin) overnight at $37^{\circ} \mathrm{C}$. Tryptic peptides were extracted with $50 \% \mathrm{ACN} / 0.1 \%$ TFA with moderate sonication for $15 \mathrm{~min}$. The extracted solutions were pooled, vacuum dried and re-dissolved in $0.1 \%$ TFA followed by injecting to the Q-TOF Ultima Global mass spectrometer (Micromass, Manchester, UK) as described before [52].

The data were acquired with the MassLynx (v 4.0) software on a Windows NT PC and further processed using ProteinLynx Global Server (PLGS, v 2.2, Micromass, Manchester, UK) as PKL (peak list) under the following settings; Electrospray, centroid $80 \%$ with minimum peak width 4 channel, noise reduction $10 \%$, Savitzky-Golay, MSMS, medium deisotoping with $3 \%$ threshold, no noise reduction and no smoothing. The peak lists were searched using the online MASCOT (http://www. matrixscience.com) algorithm against the SwissProt 55.5 (389046 sequences; 139778124 residues).

The data were retrieved against the whole database with search parameters set as follows: enzyme, trypsin; allowance of up to one missed cleavage peptide; mass tolerance $\pm 0.5 \mathrm{Da}$ and MS/MS tolerance $\pm 0.5 \mathrm{Da}$; modifications of cysteine carboamidomethylation and methionine oxidation when appropriate with auto hits allowed only significant hits to be reported.

\section{Protein data Set and pathway enrichment analysis}

Swiss-Prot accession numbers of identified differentially expressed membrane proteins, retrieved by MASCOT were used to investigate similarities in protein expression alterations between stages. To investigate enrichment of specific pathways in the altered/PTMed protein expression data set, "WEB-based GEneSeTAnaLysis Toolkit” (WEBGESTALT) at http://bioinfo.vanderbilt. edu/webgestalt/ was used [53]. Protein expression changes are not isolated events, we therefore hypothesized that differentially expressed CYB5A protein may interact with others and play a role in oncogenesis.
STRING 8.3 (http://string-db.org/) was used to explore the biological associations among the differentially expressed proteins [54].

\section{Additional files}

Additional file 1: Expression graphs and MS/MS of differentially expressed proteins in HCC along with peptide sequence identified.

Additional file 2: Microscope and Camera Setting.

\section{Abbreviations}

HCC: Hepatocellular carcinoma; ESI-Q-TOF MS/MS: Electrospray ionization quadrupole time of flight tandem mass spectrometry; CYB5A: Cytochrome b5A; ATPD: ATP synthase subunit delta; HBB: Hemoglobin subunit beta; KEGG: Kyoto encyclopedia of genes and genomes; iNOS: Nitric oxide synthase; PTM: Post translational modification; FIBB: Fibrinogen beta chain; QCR1: Cytochrome b-c1 complex subunit 1; CYB4R3: Cytochrome b5 reductase 3; CYP17A1: Cytochrome P450 family 17, subfamily A, polypeptide 1; CYP3A5: Cytochrome P450 family 3, subfamily A, polypeptide 5; FADS2: Fatty acid desaturase 2; SCD: Stearoyl-CoA desaturase; ACSL: Acyl-CoA synthetase; NO: Nitric oxide.

\section{Competing interests}

The authors declare that they have no competing interests.

\section{Authors' contributions}

NA and MAR designed the study, experiments, acquisition of data and finalized the manuscript. RK performed all experimental work (two dimensional electrophoresis, Immunohistochemistry, western blotting, MS), data analysis, interpretation and draft of the manuscript. YJYW, JF, ABAK and AMN provided samples and clinical data. AZ provided lab facility. SZ involved in S-nitrosylation technique development. All authors read and approved the final manuscript.

\section{Acknowledgments}

The authors gratefully acknowledged excellent technical assistance and expert opinion regarding ESI-QTOF MS/MS provided by AR Asif (Department of Clinical Chemistry, University Medical Center Goettingen, Goettingen, Germany) and the working facility provided by KIBGE, University of Karachi. The work was fully supported by the Higher Education Commission (HEC), Pakistan Grant No. 725 to MA. R and N A.

\section{Author details}

${ }^{1}$ Neurochemistry Research Unit Laboratory, Department of Biochemistry, University of Karachi, Karachi, Pakistan. ${ }^{2}$ The University of Kansas Medical Center, Kansas City Lawrence, Kansas, USA. ${ }^{3}$ The Karachi Institute of Biotechnology and Genetic Engineering, (KIBGE), University of Karachi, Karachi, Pakistan.

\section{Received: 17 September 2012 Accepted: 24 May 2013}

Published: 1 June 2013

\section{References}

1. Llovet JM, Burroughs A, Bruix J: Hepatocellular carcinoma. Lancet 2003, 362:1907-1917.

2. Okuda K: Hepatocellular carcinoma. J Hepatol 2000, 32:225-237.

3. El-Serag HB, Mason AC: Rising incidence of hepatocellular carcinoma in the United States. N Engl J Med 1999, 340:745-750.

4. Di Bisceglie AM, Simpson LH, Lotze MT, Hoofnagle JH: Development of hepatocellular carcinoma among patients with chronic liver disease due to hepatitis C viral infection. J Clin Gastroenterol 1994, 19:222-226.

5. Marquardt JU, Galle PR, Teufel A: Hepatocellular carcinoma: molecular pathogenesis and novel targets for therapy. Dtsch Med Wochenschr 2012, 137:855-860.

6. el Tazi M, Essadi I, M'rabti H, Touyar A, Errihani PH: Systemic treatment and targeted therapy in patients with advanced hepatocellular carcinoma. N Am J Med Sci 2011, 3:167-175. 
7. Dumpis U, Kovalova Z, Jansons J, Cupane L, Sominskaya I, Michailova M, Karayiannis P, Gardovska D, Viazov S, Ross S, Roggendorf M, Pumpens P: An outbreak of HBV and HCV infection in a paediatric oncology ward: epidemiological investigations and prevention of further spread. J Med Virol 2003, 69:331-338.

8. Seow TK, Liang RC, Leow CK, Chung MC: Hepatocellular carcinoma: from bedside to proteomics. Proteomics 2001, 1:1249-1263.

9. Shin BK, Hong W, Hanash S: Proteomics approaches to uncover the repertoire of circulating biomarkers for breast cancer. J Mammary Gland Biol Neoplasia 2002, 7:407-413.

10. Song P, Tobe RG, Inagaki Y, Kokudo N, Hasegawa K, Sugawara Y, Tang W: The management of hepatocellular carcinoma around the world: a comparison of guidelines from 2001 to 2011. Liver Int 2012, 32:1053-1063.

11. Steel LF, Mattu TS, Mehta A, Hebestreit H, Dwek R, Evans AA, London WT, Block T: A proteomic approach for the discovery of early detection markers of hepatocellular carcinoma. Dis Markers 2001, 17:179-189.

12. Berg T, von Wagner M, Nasser S, Sarrazin C, Heintges T, Gerlach T, Buggisch P, Goeser T, Rasenack J, Pape GR, Schmidt WE, Kallinowski B, Klinker H, Spengler U, Martus P, Alshuth U, Zeuzem S: Extended treatment duration for hepatitis $C$ virus type 1: comparing 48 versus 72 weeks of peginterferon-alfa-2a plus ribavirin. Gastroenterology 2006, 130:1086-1097.

13. Zhou G, Li H, DeCamp D, Chen S, Shu H, Gong Y, Flaig M, Gillespie JW, Hu N, Taylor PR, Emmert-Buck MR, Liotta LA, Petricoin EF 3rd, Zhao Y: 2D differential in-gel electrophoresis for the identification of esophageal scans cell cancer-specific protein markers. Mol Cell Proteomics 2002, 1:117-124.

14. Mínguez B, Lachenmayer A: Diagnostic and prognostic molecular markers in hepatocellular carcinoma. Dis Marker 2011, 31:181-190.

15. Chan DW, Colantonio DA: Clinical proteomics:cancer diagnostics? J Clin Ligand Assay 2005, 28:35-37.

16. Zhang Z, Chan DW: Cancer proteomics:in pursuit of "true" biomarker discovery. (Editorial). cancer epidemiol. Biomark Prevent 2005, $14: 2283-2286$

17. Song Y, Hao Y, Sun A, Li T, Li W, Guo L, Yan Y, Geng C, Chen N, Zhong F, Wei $H$, Jiang $Y$, He F: Sample preparation project for the subcellular proteome of mouse liver. Proteomics 2006, 6:5269-5277.

18. Lee TY, Chen YJ, Lu TC, Huang HD, Chen YJ: SNOSite: exploiting maximal dependence decomposition to identify cysteine S-nitrosylation with substrate site specificity. PLoSOne 2011, 6:e21849.

19. Majano PL, García-Monzón C, López-Cabrera M, Lara-Pezzi E, Fernández-Ruiz E, García-Iglesias C, Borque MJ, Moreno-Otero R: Inducible nitric oxide synthase expression in chronic viral hepatitis. Evidence for a virusinduced gene upregulation. J Clin Invest 1998, 101:1343-1352.

20. Rahman MA, Dhar DK, Yamaguchi E, Maruyama S, Sato T, Hayashi H, Ono T, Yamanoi A, Kohno H, Nagasue N: Coexpression of inducible nitric oxide synthase and COX-2 in hepatocellular carcinoma and surrounding liver: possible involvement of COX-2 in the angiogenesis of hepatitis C viruspositive cases. Clin Cancer Res 2001, 7:1325-1332.

21. Hussain SP, Raja K, Amstad PA, Sawyer M, Trudel LJ, Wogan GN, Hofseth L Shields PG, Billiar TR, Trautwein C, Hohler T, Galle PR, Phillips DH, Markin R, Marrogi AJ, Harris CC: Increased p53 mutation load in nontumorous human liver of wilson disease and hemochromatosis: oxyradical overload diseases. Proc Natl Acad Sci USA 2000, 97:12770-12775.

22. Bogdan C: Nitric oxide and the immune response. Nat Immunol 2001, 2:907-916.

23. Gaston B, Singel D, Doctor A, Stamler JS: S -nitrosothiol signaling in respiratory biology. Am J Respir Crit Care Med 2006, 173:1186-1193.

24. Foster MW, Hess DT, Stamler JS: Protein S - nitrosylation in health and disease: a current perspective. Trends Mol Med 2009, 15:391-404.

25. Wei W, Li B, Hanes MA, Kakar S, Chen X, Liu L: S -nitrosylation from GSNOR deficiency impairs DNA repair and promotes hepatocarcinogenesis. Sci Trans/ Med 2010, 2(19):19ra13. doi:10.1126/scitranslmed.3000328.

26. Hess DT, Matsumoto A, Kim SO, Marshall HE, Stamler JS: Protein Snitrosylation: purview and parameters. Nat Rev Mol Cell Biol 2005, 6:150-166.

27. Liu L, Xu-Welliver M, Kanugula S, Pegg AE: Inactivation and degradation of O(6)-alkylguanine-DNA alkyltransferase after reaction with nitric oxide. Cancer Res 2002, 62:3037-3043.

28. Fukumura D, Kashiwagi S, Jain RK: The role of nitric oxide in tumour progression. Nat Rev Cancer 2006, 6:521-534.
29. Pedrazzini E, Villa A, Longhi R, Bulbarelli A, Borgese N: Mechanism of residence of cytochrome $b(5)$, a tail-anchored protein, in the endoplasmic reticulum. J Cell Biol 2000, 148:899-914.

30. Pandey AV, Miller WL: Regulation of 17, 20 lyase activity by cytochrome b5 and by serine phosphorylation of P450c17. J Biol Chem 2005, 280:13265-13271.

31. Stringer RA, Strain-Damerell C, Nicklin P, Houston JB: Evaluation of recombinant cytochrome P450 enzymes as an in vitro system for metabolic clearance predictions. Drug Metab Dispos 2009, 37:1025-1034.

32. Schenkman JB, Jansson I: The many roles of cytochrome b5. Pharmacol Ther 2003, 97:139-152.

33. Porter TD: The roles of cytochrome b5 in cytochrome $\mathrm{P} 450$ reactions. J Biochem Mol Toxicol 2002, 16:311-316.

34. Yamazaki H, Nakamura M, Komatsu T, Ohyama K, Hatanaka N, Asahi S, Shimada N, Guengerich FP, Shimada T, Nakajima M, Yokoi T: Roles of nadph-p450 reductase and apo- and holo-cytochrome b5 on xenobiotics oxidations catalyzed by 12 recombinant human cytochrome p450s expressed in membranes of Escherichia coli. Protein Expr Purif 2002, 24:329-337.

35. Miller WL, Auchus RJ: The molecular biology, biochemistry, and physiology of human steroidogenesis and its disorders. Endocr Rev 2011, 32:81-151.

36. Blanc M, Hsieh WY, Robertson KA, Watterson S, Shui G, Lacaze $P$, Khondoker M, Dickinson P, Sing G, RodrÃguez-MartÃn S, Phelan P, Forster T, Strobl B, Muller M, Riemersma R, Osborne T, Wenk MR, Angulo A, Ghazal P: Host defense against viral infection involves interferon mediated downregulation of sterol biosynthesis. PLOS Biol 2011, 9:e1000598.

37. Finn RD, McLaughlin LA, Hughes C, Song C, Henderson CJ, RolandWolf C: Cytochrome $b$ null mouse: a new model for studying inherited skin disorders and the role of unsaturated fattyacids in normal homeostasis. Transgenic Res 2011, 20:491-502.

38. Abe K, Kimura S, Kizawa R, Anan FK, Sugita Y: Amino acid sequences of cytochrome b5 from human, porcine, and bovine erythrocytes and comparison with liver microsomal cytochrome b5. J Biochem 1985, 97:1659-1668.

39. Takematsu H, Kawano T, Koyama S, Kozutsumi Y, Suzuki A, Kawasaki T: Reaction mechanism underlying CMP-N-acetylneuraminic acid hydroxylation in mouse liver: formation of a ternary complex of cytochrome b5, CMP-N-acetylneuraminic acid, and a hydroxylation enzyme. J Biochem 1994, 115:381-386.

40. Guiard B, Groudinsky O, Lederer F: Homology between bakers' yeast cytochrome b2 and liver microsomal cytochrome b5. Proc Natl Acad Sci USA 1974, 71:2539-2543.

41. Guiard B, Lederer F: The "b5-like" domain from chicken- liver sulfite oxidase: a new case of common ancestral origin with liver cytochrome b5 and bakers' yeast cytochrome b5 core. Eur J Biochem 1977, 74:181-190.

42. Yantsevich AV, Gilep AA, Usanov SA: Mechanism of electron transfer in fusion protein cytochrome b5-NADH_cytochrome b5 reductase. Biochemistry (Mosc) 2008, 73:1096-1107.

43. Dunn TM, Haak D, Monaghan E, Beeler TJ: Synthesis of monohydroxylated inositolphosphorylceramide (IPC-C) in Saccharomyces cerevisiae requires $\mathrm{Scs7p}$, a protein with both a cytochrome b5-like domain and a hydroxylase/desaturase domain. Yeast 1998, 14:311-321.

44. Wai PY, Kuo PC: Intersecting pathways in inflammation and cancer: Hepatocellular carcinoma as a paradigm. World J Clin Oncol 2012, 3:15-23.

45. Hanash SM: Biomedical applications of two dimensional electrophoresis using immobilized pH gradients: Current status. Electrophoresis 2000, 21:1202-1209.

46. Reymond MA, Sanchez JC, Hughes GJ, Günther K, Riese J, Tortola S, Peinado MA, Kirchner T, Hohenberger W, Hochstrasser DF, Köckerling F: Standardized characterization of gene expression in human colorectal epithelium by two dimensional electrophoresis. Electrophoresis 1997, 18:842-848.

47. Keyes SR, Alfano JA, Jansson I, Cinti DL: Rat liver microsomal elongation of fattyacids. J Biochem 1979, 254:7778-7784.

48. Gan L, von Moltke LL, Trepanier LA, Harmatz JS, Greenblatt DJ, Court MH: Role of NADPH-cytochrome P450 reductase and cytochrome-b5/NADHb5 reductase in variability of CYP3A activity in human liver microsomes. Drug Metab Dispos 2009, 37:90-96. 
49. Lewis DF, Ito Y: Human cytochromes P450 in the metabolism of drugs: new molecular models of enzyme-substrate interactions.

Expert Opin Drug Metab Toxicol 2008, 4:1181-1186.

50. Blum H, Beier H, Gross HJ: Silver staining of proteins in polyacrylamide gels. Electrophoresis 1987, 8:93-99.

51. Shevchenko A, Wilm M, Vorm O, Mann M: Mass spectrometric sequencing of proteins silver-stained polyacrylamide gels. Anal Chem 1996, 68:850-858.

52. Asif AR, Oellerich M, Amstrong WW, Gross U, Reichard U: Analysis of the cellular Aspergillusfumigatus proteome that reacts with sera from rabbits developing an acquired immunity after experimental aspergillosis. Electrophoresis 2010, 31:1947-1958.

53. Zhang B, Kirov S, Snoddy J: WebGestalt: an integrated system for exploring gene sets in various biological contexts. Nucleic Acids Res 2005, 33:741-748.

54. Jensen $\sqcup$, Kuhn M, Stark M, Chaffron S, Creevey C, Muller J, Doerks T, Julien P, Roth A, Simonovic M, Bork P, von Mering C: STRING 8-a global view on proteins and their functional interactions in 630 organisms. Nucleic Acids Res 2009, 37:412-416.

doi:10.1186/1559-0275-10-6

Cite this article as: Khan et al:: Protein expression profiling of nuclear membrane protein reveals potential biomarker of human hepatocellular carcinoma. Clinical Proteomics 2013 10:6.

\section{Submit your next manuscript to BioMed Central and take full advantage of:}

- Convenient online submission

- Thorough peer review

- No space constraints or color figure charges

- Immediate publication on acceptance

- Inclusion in PubMed, CAS, Scopus and Google Scholar

- Research which is freely available for redistribution 